\title{
Multigram synthesis of
}

\section{the tetrasubsituted dihydrobenzofuran GSK973}

\section{enabled by high throughput experimentation and a}

\section{Claisen rearrangement in flow.}

Catherine M. Alder, ${ }^{* *}$ Matthew Gray, ${ }^{\# t}$ Chelsea A. Huff, ${ }^{\S}$ Calvin O. Manning, ${ }^{\#}$ Alex Preston,

${ }^{\dagger}$ Philip Rushworth, ${ }^{\#}$ Leanna E. Shuster ${ }^{\neq t}$ Robert J. Watson, ${ }^{\dagger}$ Katherine M. P. Wheelhouse, ${ }^{\#}$ Glynn D. Williams, ${ }^{\#+}$ Emmanuel H. Demont. ${ }^{\dagger}$

${ }^{¥}$ UK Green Chemistry, ${ }^{\#}$ API Chemistry U.K, ${ }^{\dagger}$ Epigenetics Discovery Performance Unit, Immunoinflammation Therapy Area Unit, GlaxoSmithKline, Medicines Research Centre, Stevenage, Hertfordshire, SG1 2NY, U.K; ${ }^{\S}$ Discovery Automation Platform Chemistry, ${ }^{\neq}$US Green Chemistry, GlaxoSmithKline, 1250 S. Collegeville Rd, Collegeville, PA 19426, USA.

* Email: catherine.m.alder@gsk.com 


\section{Supporting Information}

\section{Content:}

Gas-phase ab initio calculations on cis-trans thermodynamic ratios

Synthesis of (1R,5S,6r)-3-Oxabicyclo[3.1.0]hexan-6-amine

Green chemistry metrics

References

S14 


\section{Gas-phase ab initio calculations on cis-trans thermodynamic ratios}

A cut-down model system was used for these calculations, which were performed at B3LYPD3 6-31g** in the gas-phase using Jaguar v10.4 within Maestro v2019.02 (Schrodinger Inc).
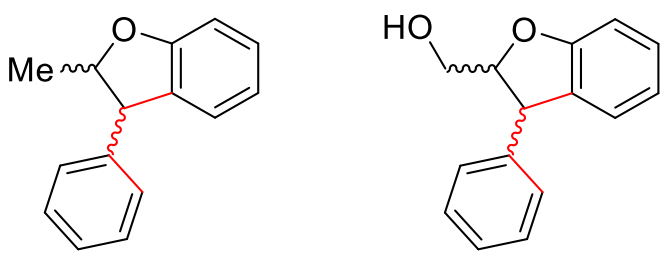

For the methyl analogue, trans and cis stereoisomers were built. For trans, 4 alternative input structures were created, with the dihydrofuran ring in either an up or down pucker, and with the pendant phenyl in one of two different torsions shown in red above $+/-\sim 30$ degrees. The 4 input structures were energy minimised, converging to two local minima, one for each pucker, one more stable than the other by $0.75 \mathrm{kcal} / \mathrm{mol}$ :

Pucker 1: -655.3026 Hartrees

Pucker 2: -655.3014 Hartrees

Similarly, for cis, 4 input structures were created and energy minimised, converging to two local minima of equivalent energy:

Pucker 1: -655.3009 Hartrees

Pucker 2: -655.3003 Hartrees 
The minima of the cis and trans conformers were then compared. The trans was slightly more stable than cis (-655.3026 vs -655.3009 Hatrees, or $1.1 \mathrm{kcal} / \mathrm{mol})$ corresponding to a 6 -fold excess of the trans form.

A similar approach was used for the hydroxymethyl analogue. Starting from the optimised minimum-energy conformer for both cis and trans methyl analogues, the hydroxyl group was added and spun using a relaxed $2 \mathrm{~d}$ torsion scan in 30 degree increments around the $\mathrm{CH}_{2}-\mathrm{OH}$ and the $\mathrm{CH}-\mathrm{CH}_{2} \mathrm{OH}$ bond. The lowest energy conformation of the trans form $(-730.5162$ Hartrees) was more stable than the cis $(-730.5125$ Hartrees) by $2.3 \mathrm{kcal} / \mathrm{mol}$, corresponding to a 49-fold excess of the trans form over the cis.

Considering the approximations these results are in very close agreement with the experimental thermodynamic ratios. It is possible that the difference between the methyl and the hydroxymethyl analogues arises from a stabilisation of the low-energy hydroxymethyl conformer by charge-charge interactions between the hydroxy $\mathrm{OH}$ and a lone pair on the saturated furan ring, which is present in the lowest energy conformer of the trans but not the cis form, although the gas phase calculation would not take account of solvation. 


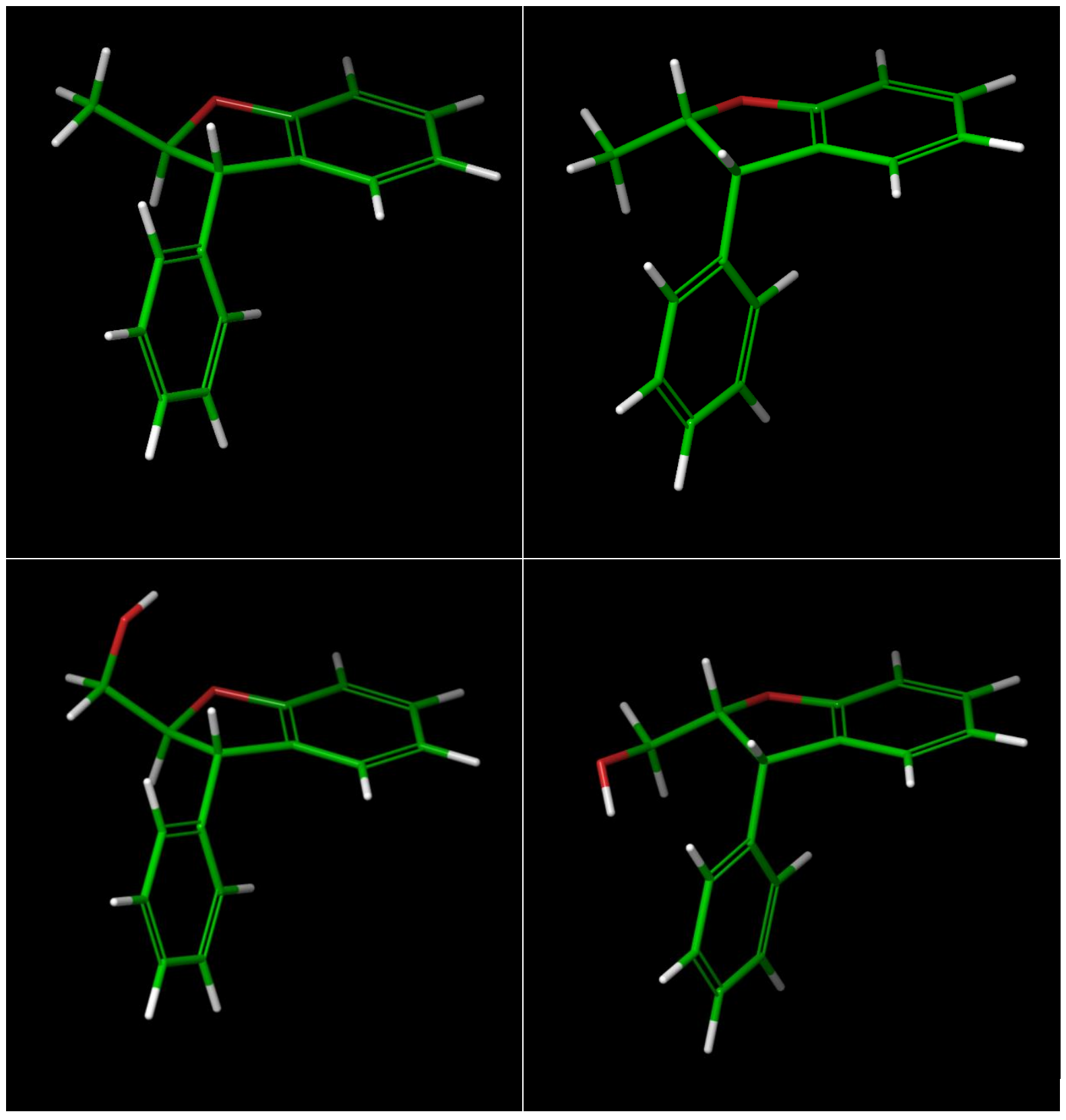

Figure S1: Minimum-energy conformers of the cis and trans stereoisomers of cut-down versions of $\mathbf{1 0}$ and $\mathbf{1 9}$ 


\section{Synthesis of (1R,5S,6r)-3-Oxabicyclo[3.1.0]hexan-6-amine}

Step 1: Ethyl (1R,5S,6r)-3-oxabicyclo[3.1.0]hexane-6-carboxylate<smiles>CCOC(=O)[C@H]1CCOC[C@H]1C</smiles>

Ethyl diazoacetate $(8.6 \mathrm{~g}, 76 \mathrm{mmol})$ in $\mathrm{CH}_{2} \mathrm{Cl}_{2}(200 \mathrm{~mL})$ was added at room temperature dropwise over $4 \mathrm{~h}$ to a solution of 2,5-dihydrofuran (5.3 g, $76 \mathrm{mmol})$ and rhodium(II) acetate dimer $(1.67 \mathrm{~g}, 3.78 \mathrm{mmol})$ in $\mathrm{CH}_{2} \mathrm{Cl}_{2}(400 \mathrm{~mL})$ under nitrogen. Once the addition was complete, the mixture was stirred at this temperature for $18 \mathrm{~h}$ then was filtered through celite and concentrated in vacuo to give a dark green oil. Purification of this residue by flash chromatography on silica gel (110 g column, gradient: 0 to $30 \%$ EtOAc in hexanes) gave ethyl (1R,5S,6r)-3-oxabicyclo[3.1.0]hexane-6-carboxylate $(3.2 \mathrm{~g}, 27 \%)$ as a colourless liquid.

LCMS (method formic): Retention time $0.75 \min ,[\mathrm{M}+\mathrm{H}]^{+}=157$

${ }^{1} \mathrm{H}$ NMR (400 MHz, $\left.\mathrm{CDCl}_{3}\right) \delta \mathrm{ppm} 4.14(\mathrm{q}, J=7.3 \mathrm{~Hz}, 2 \mathrm{H}), 3.93(\mathrm{~d}, J=8.8 \mathrm{~Hz}, 2 \mathrm{H}), 3.75(\mathrm{~d}$, $J=8.3 \mathrm{~Hz}, 2 \mathrm{H}), 2.14-2.18(\mathrm{~m}, 2 \mathrm{H}), 1.58-1.63(\mathrm{~m}, 1 \mathrm{H}), 1.25-1.29(\mathrm{~m}, 3 \mathrm{H})$.

Step 2: (1R,5S,6r)-3-oxabicyclo[3.1.0]hexane-6-carboxylic acid

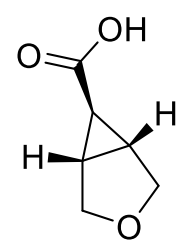

A solution of (1R,5S,6r)-ethyl 3-oxabicyclo[3.1.0]hexane-6-carboxylate (5.0 g, $32 \mathrm{mmol})$ in EtOH $(50 \mathrm{~mL})$ was treated at room temperature with a $2 \mathrm{~N} \mathrm{NaOH}$ aqueous solution $(48 \mathrm{~mL}, 96$ mmol) and the resulting mixture was stirred at this temperature for $18 \mathrm{~h}$, then concentrated to 
half volume in vacuo. The resulting solution was washed with $\mathrm{Et}_{2} \mathrm{O}(50 \mathrm{~mL})$, then acidified with a $2 \mathrm{~N} \mathrm{HCl}$ aqueous solution to $\mathrm{pH} 4$ and extracted with EtOAc $(3 \mathrm{x} 100 \mathrm{~mL})$. The combined organics were dried over $\mathrm{MgSO}_{4}$ and concentrated in vacuo to give (1R,5S,6r)-3oxabicyclo[3.1.0]hexane-6-carboxylic acid (3.9 g, 95\%) as a colourless solid.

${ }^{1} \mathrm{H}$ NMR (400 MHz, DMSO-d $\left.d_{6}\right) \delta$ ppm $12.19(\mathrm{~s}, 1 \mathrm{H}), 3.81(\mathrm{~d}, J=8.8 \mathrm{~Hz}, 2 \mathrm{H}), 3.62(\mathrm{~d}, J=8.8$ $\mathrm{Hz}, 2 \mathrm{H}), 2.08(\mathrm{dd}, J=2.7,1.7 \mathrm{~Hz}, 2 \mathrm{H}), 1.32(\mathrm{t}, J=3.2 \mathrm{~Hz}, 1 \mathrm{H})$.

Step 3: tert-Butyl (1R,5S,6r)-3-oxabicyclo[3.1.0]hexan-6-ylcarbamate

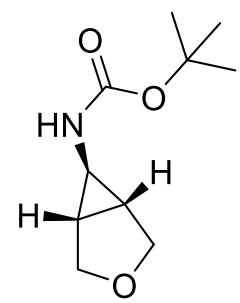

A suspension of (1R,5S,6r)-3-oxabicyclo[3.1.0]hexane-6-carboxylic acid (3.90 g, $30.4 \mathrm{mmol})$ in toluene $(20 \mathrm{~mL})$ at room temperature was treated with $\mathrm{NEt}_{3}(12.7 \mathrm{~mL}, 91.0 \mathrm{mmol})$ and diphenyl phosphorazidate $(7.85 \mathrm{~mL}, 36.5 \mathrm{mmol})$ and the resulting mixture was stirred for 20 min at this temperature then tert-butanol $(20.0 \mathrm{~mL}, 209 \mathrm{mmol})$ was added. The solution was then heated at reflux for $5 \mathrm{~h}$ before being cooled to room temperature. The mixture was diluted with EtOAc $(50 \mathrm{~mL})$ and the organic phase was washed with water $(50 \mathrm{~mL})$, then with a saturated $\mathrm{NaHCO}_{3}$ solution $\left(50 \mathrm{~mL}\right.$ ) before being dried over $\mathrm{MgSO}_{4}$ and concentrated in vacuo to give tert-butyl (1R,5S,6r)-3-oxabicyclo[3.1.0]hexan-6-ylcarbamate $(3.4 \mathrm{~g}, 56 \%)$ as a beige crystalline solid.

${ }^{1} \mathrm{H}$ NMR (400 MHz, DMSO- $\left.d_{6}\right) \delta$ ppm 6.99 (br. s, $\left.1 \mathrm{H}\right), 3.77(\mathrm{~d}, J=8.3 \mathrm{~Hz}, 2 \mathrm{H}), 3.58(\mathrm{~d}, J=$ $8.3 \mathrm{~Hz}, 2 \mathrm{H}), 2.18$ (br s, 1H), $1.70(\mathrm{td}, J=2.1,1.3 \mathrm{~Hz}, 2 \mathrm{H}), 1.39(\mathrm{~s}, 9 \mathrm{H})$,

Step 4: (1R,5S,6r)-3-Oxabicyclo[3.1.0]hexan-6-amine 


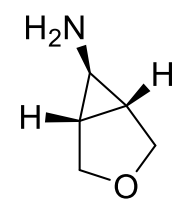

A solution of tert-butyl (1R,5S,6r)-3-oxabicyclo[3.1.0]hexan-6-ylcarbamate (3.40 g, 17.1 $\mathrm{mmol})$ in $\mathrm{CH}_{2} \mathrm{Cl}_{2}(20 \mathrm{~mL})$ at room temperature was treated with a $4 \mathrm{~N} \mathrm{HCl}$ solution in dioxane $(12.8 \mathrm{~mL}, 51.2 \mathrm{mmol})$ and the resulting mixture was stirred for $2 \mathrm{~h}$ at this temperature then the solvent was evaporated in vacuo. The residue was dissolved in $\mathrm{MeOH}$ and loaded onto a $50 \mathrm{~g}$ SCX cartridge, which was washed with $\mathrm{MeOH}(100 \mathrm{~mL})$, then eluted with $2 \mathrm{~N} \mathrm{NH}_{3}$ in $\mathrm{MeOH}$. The eluant was evaporated in vacuo to give (1R,5S,6r)-3-oxabicyclo[3.1.0]hexan-6-amine (1.6 $\mathrm{g}, 95 \%)$ as a pale yellow liquid.

${ }^{1} \mathrm{H}$ NMR (400 MHz, $\left.\mathrm{CDCl}_{3}\right) \delta \mathrm{ppm} 3.86(\mathrm{~d}, J=8.3 \mathrm{~Hz}, 2 \mathrm{H}), 3.68(\mathrm{~d}, J=8.3 \mathrm{~Hz}, 2 \mathrm{H}), 2.22(\mathrm{t}$, $J=2.0 \mathrm{~Hz}, 1 \mathrm{H}), 1.56-1.64$ (m, 2H), 1.48 (br. s, 2H). 


\section{Green Chemistry Metrics}

\section{1) General}

The following formulae were used for calculating Atom Economy (AE), Reaction Mass Efficiency (RME) and Process Mass Intensity (PMI). ${ }^{1}$

$$
\begin{gathered}
A E=\frac{\text { Molecular Weight of Product }}{\text { Total Molecular Weight of Reactants }} \times 100 \\
R M E=\frac{\text { Mass of Isolated Product }}{\text { Total Mass of Reactants }} \times 100 \\
P M I=\frac{\text { Total Mass in a Process or Process Step }}{\text { Mass of Product }}
\end{gathered}
$$

For the calculation of cumulative metrics over several synthetic steps, the following formulae were used:

$$
A+B \rightarrow C \quad C+D \rightarrow E
$$

$M W=$ molecular weight of compound; $m=$ weight of component.

$$
\begin{gathered}
A E(E)=\frac{M W(E)}{M W(A)+M W(B)+M W(D)} \times 100=\frac{M W(E)}{\frac{M W(C)}{\frac{A E(C)}{100}}+M W(D)} \times 100 \\
R M E(E)=\frac{m(E)}{m(D)+m(C)} \times 100=\frac{m(E)}{\frac{m(C)}{\frac{R M E(C)}{100}}+m(D)} \times 100 \\
P M I(E)=\frac{m(C) \times M I(C)+\text { Total Mass of Other Chemicals in the Step }}{\text { Mass of Product }}
\end{gathered}
$$

The specific PMI for Reaction, Solvents and Workup were calculated using the PMI formula using only the corresponding data (total mass of reaction components, solvents and work-up components). 
This general formula has been put into an excel spreadsheet based on the CHEM21 template ${ }^{2-}$ with the addition of colour coding of reagents, acids/bases and solvents using the GSK guides. ${ }^{3}$ Some general assumption made when calculating some substrate amounts.

\section{$\underline{\text { Rules used to calculate metrics were some details missing }}$}

A saturated brine solution is used in workup (purification). We consider concentration of $26.5 \mathrm{~g}$ $\mathrm{NaCl} / 100 \mathrm{ml}$ water.

For example, $500 \mathrm{ml}$ of brine would be

- $5^{*} 26.5 \mathrm{~g}=132.5 \mathrm{~g}$ of $\mathrm{NaCl}$ in $500 \mathrm{ml}$

- Water would be equal to $500 \mathrm{ml}-132.5 \mathrm{~g}=367.5 \mathrm{~g}$ of water.

A saturated solution of $\mathrm{NaHCO} 3$ is used in to neutralise the $\mathrm{pH}$ during workup (purification). We consider concentration of $8.28 \mathrm{~g} / 100 \mathrm{ml}$ water.

$2 \mathrm{~N} \mathrm{HCl}$ solution $=2 * \mathrm{MW}$ in $1 \mathrm{~L}$ or $1000 \mathrm{~mL}$

For example, $500 \mathrm{ml}$ of $2 \mathrm{~N} \mathrm{HCl}$

- $2 * 36.46 *(500 / 1000)=36.46 \mathrm{~g}$ of $\mathrm{HCl}$ in $500 \mathrm{ml}$

- $500-36.46=463.54 \mathrm{~g}$ of water

Solid washes if no value given use reaction volumes.

Any drying or filtering agent $\left(\mathrm{Na}_{2} \mathrm{SO} 4, \mathrm{MgSO}_{4}, \&\right.$ Celite $)$ we consider these are used in $10 \%$ of the isolated mass of product with the corresponding step.

Partitioned volumes between water and organic for work up assume both match reaction volume unless stated.

When a percentage range is used the mid-point is used.

Chromatography - if a gradient used the mid-point percentage is taken and treat as if an isocratic method used.

The solid phase of column chromatography, if not indicated in grams, is estimated as (mass of isolated product/0.075), assuming $7.5 \%$ column loading.

The total volume of eluent phase for column chromatography, is estimated from the mass of solid phase (e.g. Silica) as:

- $\quad$ (mass of silica) $* 1.34 * 10 \mathrm{CV}$, if loading $<=1 \mathrm{~kg}$;

- $\quad$ (mass of silica) $* 1.6 * 10 \mathrm{CV}$, if loading $>1 \mathrm{~kg}$

This value is then split between the solvent components based on ratio. If a gradient is applied, then an average between initial and final ratios is applied. 
Where multiple batches were made, a scaling factor was applied to the input materials, but the actual combined isolated material was used to calculate the yield for the step.

For example, from the Optimised Synthesis of GSK973: step 1 to make Methyl 5bromo-2-(cinnamyloxy)benzoate (14). Experiment shown uses $230 \mathrm{~g}$ of methyl 5-bromo-2hydroxybenzoate then repeated twice with $200 \mathrm{~g}$ and $95 \mathrm{~g}$ - (total $525 \mathrm{~g}$ of the methyl 5-bromo2-hydroxybenzoate) $525 / 230=2.28$. Therefore all components within the reaction are to be multipled by 2.28 to give the values used in calculating the PMI. However a combined isolated yield is disclosed and therefore use. i.e 594g of Methyl 5-bromo-2(cinnamyloxy)benzoate (14) which made the yield from the new input

Moles of Limiting reagent 525/ $231=2.27 \mathrm{~mol}$

Moles of Product $=594 / 347=1.71 \mathrm{~mol}$

$1.71 / 2.27=0.75(* 100)=75 \%$ isolated yield.

Multiplier factor used on the following optimised synthesis steps of GSK973 to the following values.

Step 1 - Alkylation - 2.28

Step 2 - Claisen rearrangement - 11.62

Step 5 - Fluorination - 3.42

Step 6 - Aminocarbonylation - 2.8

The chiral chromatography solvent volumes have been excluded from both routes as the same method was used to obtain the desired product.

Note : Starting material that make up the components of the desired product will be unclassified. Other reaction reagents are only colour coded if an evaluation for the transformation exists or feature on the GSK reagent or acid/ base guides. Drying agents, scavengers and silica will be unclassified components in colour coding.

All solvents scored as either water, or organic solvents are further classified as Green, Amber or Red based on the GSK solvent guide. 


\section{2) Final cumulative values}

Original Med Chem route to GSK973

\begin{tabular}{|l|c|}
\hline \multicolumn{2}{|c|}{ Cumulative metrics } \\
\hline Yield \% & $\mathbf{1 0 . 3}$ \\
\hline AE & 36 \\
\hline RME & 1 \\
\hline PMI Total & $\mathbf{5 8 5 8}$ \\
\hline PMI Reaction & 484 \\
\hline PMI Purification & 5374 \\
\hline
\end{tabular}

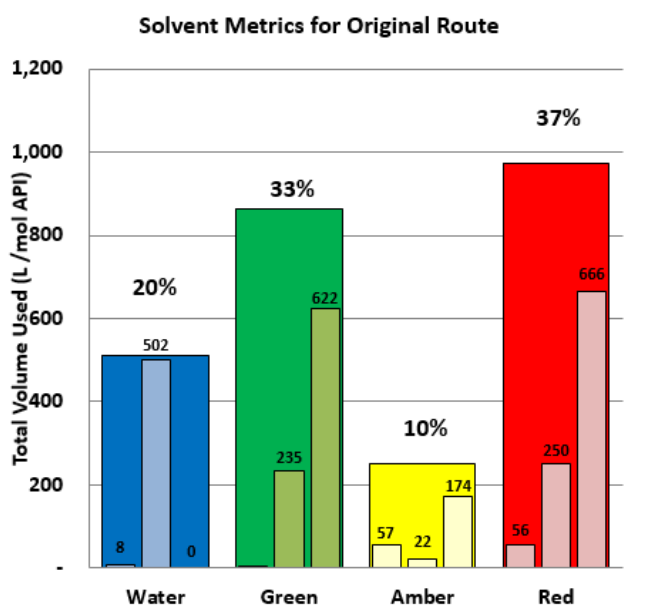

$v s$

Optimised synthesis to GSK973

\begin{tabular}{|l|c|}
\hline \multicolumn{2}{|c|}{ Cumulative metrics } \\
\hline Yield \% & $\mathbf{2 4 . 9}$ \\
\hline $\mathrm{AE}$ & 37 \\
\hline RME & 11 \\
\hline PMI Total & $\mathbf{1 2 6 0}$ \\
\hline PMI Reaction & 118 \\
\hline PMI Purification & 1142 \\
\cline { 2 - 2 }
\end{tabular}

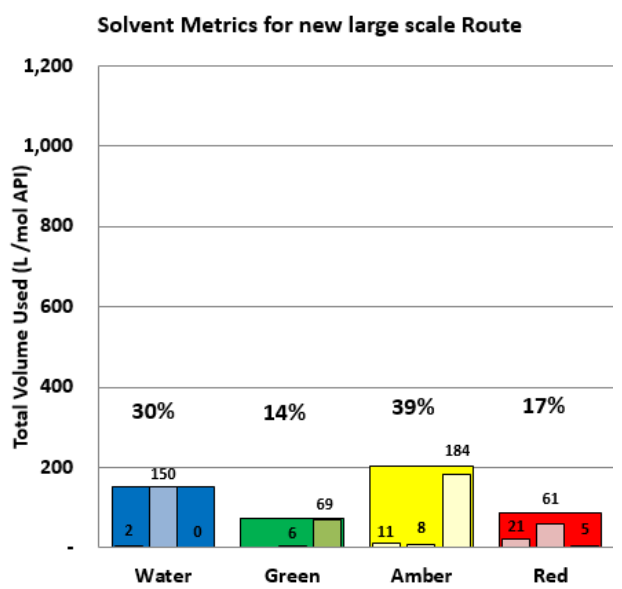

Bar chart - Each solvent bar is classified as water (blue), organic solvents - (Green, Amber and Red) are broken down further into 3 bars within the corresponding colour to represent. From left to right these correspond to

1. Reaction media volume used (L / mol Active Pharmaceutical Ingredient (API))

2. Workup and Purification volume use without Chromatography (L/ mol API)

3. Chromatography Solvents Only use (L / mol API) 
$\underline{\text { Total amount of solvents used to calculate bar charts: }}$

Original Med Chem route
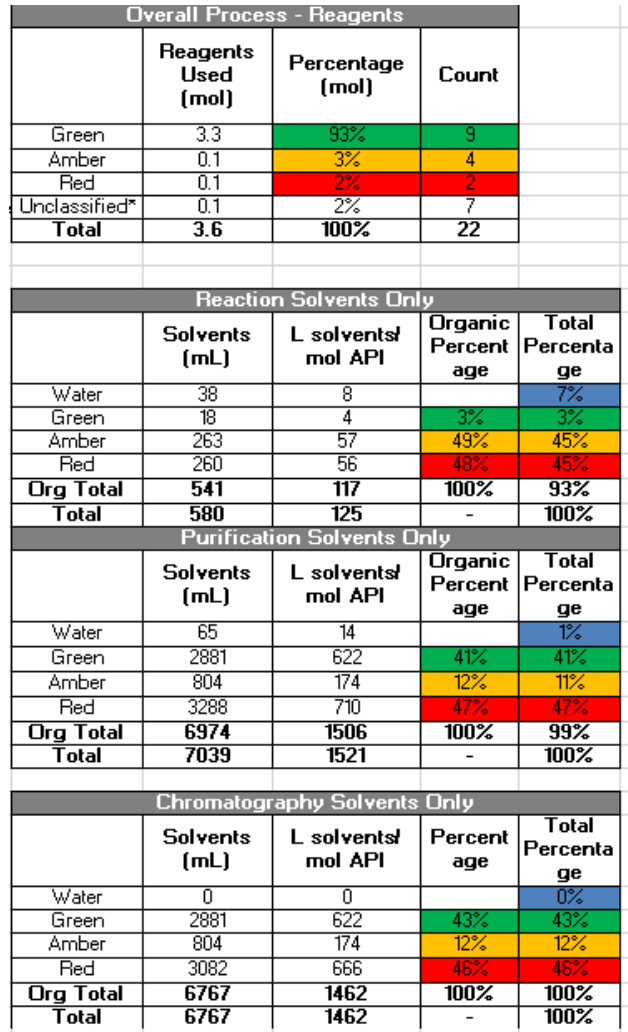
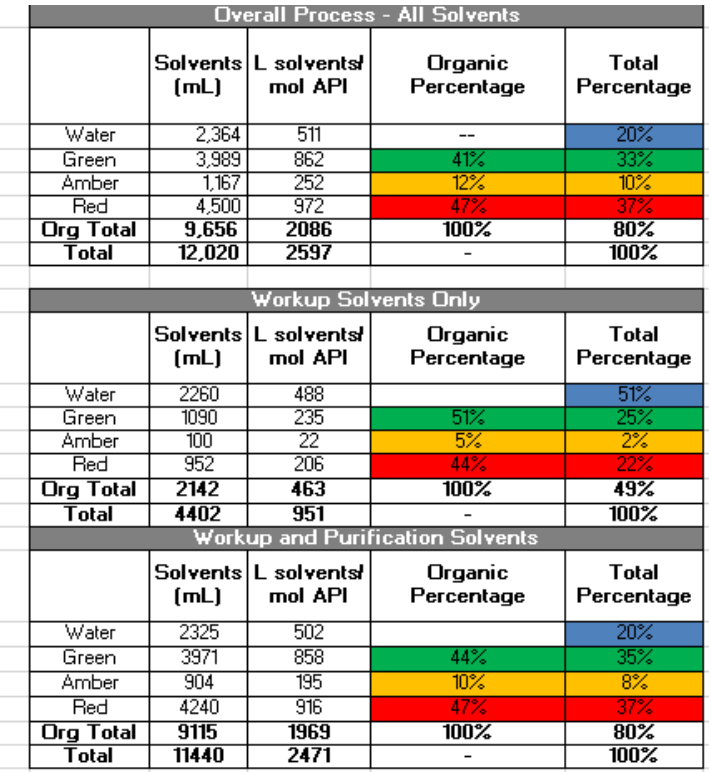

\begin{tabular}{|c|c|c|c|c|}
\hline \multicolumn{4}{|c|}{ Workup and Purification wo Chromatography } \\
\hline & $\begin{array}{c}\text { Solvents } \\
\text { (mL) }\end{array}$ & $\begin{array}{c}\text { L solventsi } \\
\text { mol API }\end{array}$ & $\begin{array}{c}\text { Organic } \\
\text { Percentage }\end{array}$ & $\begin{array}{c}\text { Total } \\
\text { Percentage }\end{array}$ \\
\hline Water & 2325 & 502 & & $50 \%$ \\
\hline Green & 1090 & 235 & $46 \%$ & $23 \%$ \\
\hline Amber & 100 & 22 & $4 \%$ & $2 \%$ \\
\hline Red & 1159 & 250 & $49 \%$ & $25 \%$ \\
\hline Org Total & $\mathbf{2 3 4 8}$ & $\mathbf{5 0 7}$ & $\mathbf{1 0 0 \%}$ & $\mathbf{5 0 \%}$ \\
\hline Total & $\mathbf{4 6 7 3}$ & $\mathbf{1 0 1 0}$ & - & $\mathbf{1 0 0 \%}$ \\
\hline
\end{tabular}

Optimised Synthesis to GSK973

\begin{tabular}{|c|c|c|c|c|}
\hline \multicolumn{4}{|c|}{ Overall Process - Reagents } & \\
\hline & $\begin{array}{c}\text { Reagents } \\
\text { Used } \\
\text { [mol] }\end{array}$ & $\begin{array}{c}\text { Percentage } \\
{[\mathrm{mol}]}\end{array}$ & Count & \\
\hline Green & 17.7 & $86 \%$ & $\overline{9}$ & \\
\hline Amber & 1.1 & $5 \%$ & 1 & \\
\hline Fied & 1.4 & $7 \%$ & 2 & \\
\hline Unclassifiedx & 0.4 & $2 \%$ & 4 & \\
\hline Total & 20.6 & $100 \%$ & 16 & \\
\hline \multirow{2}{*}{\multicolumn{5}{|c|}{ Reaction Solvents Dnly }} \\
\hline & & & & \\
\hline & $\begin{array}{l}\text { Solvents } \\
\text { [mL] }\end{array}$ & $\begin{array}{c}\text { L solvents' } \\
\text { mol API }\end{array}$ & $\begin{array}{c}\text { Organic } \\
\text { Percent } \\
\text { age }\end{array}$ & \begin{tabular}{|c|} 
Total \\
Percen \\
tage
\end{tabular} \\
\hline Water & 406 & 2 & & $5 \%$ \\
\hline Green & 0 & 0 & $0 \%$ & $0 \%$ \\
\hline Amber & 2766 & 11 & $35 \%$ & $34 \%$ \\
\hline Ried & 5057 & 21 & $65 \%$ & $61 \%$ \\
\hline Org Total & 7823 & 32 & $100 \%$ & $95 \%$ \\
\hline Total & 8229 & 34 & - & $100 \%$ \\
\hline \multicolumn{5}{|c|}{ Purification Solvents Dnly } \\
\hline & $\begin{array}{l}\text { Solvents } \\
\text { [mL] }\end{array}$ & $\begin{array}{c}\text { L solvents' } \\
\text { mol API }\end{array}$ & $\begin{array}{c}\text { Organic } \\
\text { Percent } \\
\text { age }\end{array}$ & \begin{tabular}{|c|} 
Total \\
Percen \\
tage
\end{tabular} \\
\hline Water & 12898 & 54 & & $15 \%$ \\
\hline Green & 18049 & 75 & $25 \%$ & $21 \%$ \\
\hline Amber & 45651 & 189 & $64 \%$ & $54 \%$ \\
\hline Red & 7654 & 32 & $11 \%$ & $9 \%$ \\
\hline Org Total & 71354 & 296 & $100 \%$ & $85 \%$ \\
\hline Total & 84253 & 350 & - & $100 \%$ \\
\hline \multicolumn{5}{|c|}{ Chromatography Solvents Dnly } \\
\hline & $\begin{array}{l}\text { Solvents } \\
\text { [mL] }\end{array}$ & $\begin{array}{c}\text { L solvents' } \\
\text { mol API }\end{array}$ & $\begin{array}{c}\text { Percent } \\
\text { age }\end{array}$ & \begin{tabular}{|c|} 
Total \\
Percen \\
tage
\end{tabular} \\
\hline Water & 0 & 0 & & $0 \%$ \\
\hline Green & 16549 & 69 & $27 \%$ & $27 \%$ \\
\hline Amber & 44333 & 184 & $71 \%$ & $71 \%$ \\
\hline Red & 1172 & 5 & $2 \%$ & $2 \%$ \\
\hline Org Total & 62054 & 258 & $100 \%$ & $100 \%$ \\
\hline Total & 62054 & 258 & & $100 \%$ \\
\hline
\end{tabular}
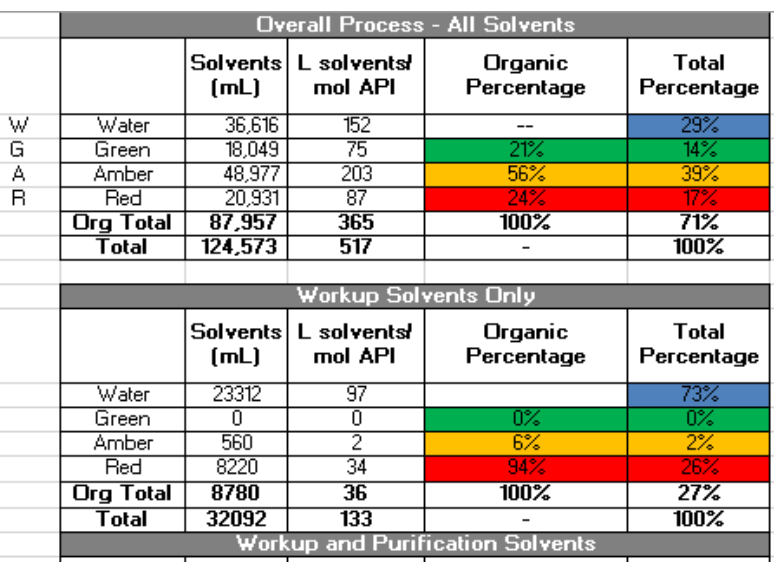

\begin{tabular}{|c|c|c|c|c|}
\hline & $\begin{array}{c}\text { Solvents } \\
\text { (mL) }\end{array}$ & $\begin{array}{c}\text { L solvents } \\
\text { mol API }\end{array}$ & $\begin{array}{c}\text { Organic } \\
\text { Percentage }\end{array}$ & $\begin{array}{c}\text { Total } \\
\text { Percentage }\end{array}$ \\
\hline Water & 36211 & 150 & & $31 \%$ \\
\hline Green & 18049 & 75 & $23 \%$ & $16 \%$ \\
\hline Amber & 46211 & 192 & $58 \%$ & $40 \%$ \\
\hline Red & 15874 & 66 & $20 \%$ & $14 \%$ \\
\hline Org Total & $\mathbf{8 0 1 3 4}$ & $\mathbf{3 3 3}$ & $\mathbf{1 0 0 \%}$ & $\mathbf{6 9 \%}$ \\
\hline Total & $\mathbf{1 1 6 3 4 5}$ & $\mathbf{4 8 3}$ & - & $\mathbf{1 0 0 \%}$ \\
\hline
\end{tabular}

\begin{tabular}{|c|c|c|c|c|}
\hline \multicolumn{5}{|c|}{ Workup and Purification wio Chromatography } \\
\hline $\begin{array}{c}\text { Solvents } \\
\text { (mL) }\end{array}$ & $\begin{array}{c}\text { L solvents } \\
\text { mol API }\end{array}$ & $\begin{array}{c}\text { Organic } \\
\text { Percentage }\end{array}$ & $\begin{array}{c}\text { Total } \\
\text { Percentage }\end{array}$ \\
\hline Water & 36211 & 150 & & $67 \%$ \\
\hline Green & 1500 & 6 & $8 \%$ & $3 \%$ \\
\hline Amber & 1878 & 8 & $10 \%$ & $3 \%$ \\
\hline Red & 14702 & 61 & $81 \%$ & $27 \%$ \\
\hline Org Total & $\mathbf{1 8 0 8 0}$ & $\mathbf{7 5}$ & $\mathbf{1 0 0 \%}$ & $\mathbf{3 3 \%}$ \\
\hline Total & $\mathbf{5 4 2 9 1}$ & $\mathbf{2 2 5}$ & - & $\mathbf{1 0 0 \%}$ \\
\hline
\end{tabular}




\section{References}

1) Constable, D. J. C.; Curzons, A. D.; Cunningham, V. L. Metrics to 'Green' Chemistry Which are the Best. Green Chem. 2002, 4, 521-527.

2) McElroy, C. R.; Constantinou, A.; Jones, L. C.; Summerton, L.; Clark, J. H., Towards a Holistic Approach to Metrics for the 21st Century Pharmaceutical Industry, Green Chem. 2015, 17, 3111-3121.

3) a) Adams, J. P.; Alder, C. M.; Andrews, I.; Bullion, A. M.; Campbell-Crawford, M.; Darcy, M. G.; Hayler, J. D.; Henderson, R. K.; Oare, C. A.; Pendrak, I.; Redman, A. M.; Shuster, L. E.; Sneddon, H. F.; Walker M. D. Development of the GSK's Reagent Guides - Embedding Sustainability into Reagent Selection. Green Chem. 2013, 15, 1542-1549

b) Henderson, R. K.; Hill, A. P.; Redman, A. M.; Sneddon, H. F. Development of GSK's Acid and Bases Selection Guides. Green Chem. 2015, 17, 945-949.

c) Alder, C. M.; Hayler, J. D.; Henderson, R. K.; Redman, A. M.; Shukla, L.; Shuster, L. E.;

Sneddon, H. F. Updating and Further Expanding GSK's Solvent Sustainability Guide. Green Chem. 2016, 18, 3879-3890. 